\title{
Ion Implantation of Calcium and Zinc in Magnesium for Biodegradable Implant Applications
}

\author{
Sahadev Somasundaram ${ }^{1}$, Mihail Ionescu ${ }^{2}$ and Bobby Kannan Mathan ${ }^{1, *}$ \\ 1 Biomaterials and Engineering Materials (BEM) Laboratory, College of Science and Engineering, \\ James Cook University, Townsville, QLD 4811, Australia; sahadev.somasundaram@my.jcu.edu.au \\ 2 Centre for Accelerator Science, Australian Nuclear Science \& Technology Organisation (ANSTO), \\ Sydney, NSW 2234, Australia; mio@ansto.gov.au \\ * Correspondence: bobby.mathan@jcu.edu.au; Tel.: +61-7-4781-5080
}

Received: 8 December 2017; Accepted: 29 December 2017; Published: 3 January 2018

\begin{abstract}
In this study, magnesium was implanted with calcium-ion and zinc-ion at fluences of $10^{15}$, $10^{16}$, and $10^{17}$ ion $\cdot \mathrm{cm}^{-2}$, and its in vitro degradation behaviour was evaluated using electrochemical techniques in simulated body fluid (SBF). Rutherford backscattering spectrometry (RBS) revealed that the implanted ions formed layers within the passive magnesium-oxide/hydroxide layers. Electrochemical impedance spectroscopy (EIS) results demonstrated that calcium-ion implantation at a fluence of $10^{15}$ ions $\cdot \mathrm{cm}^{-2}$ increased the polarisation resistance by $24 \%$, but higher fluences showed no appreciable improvement. In the case of zinc-ion implantation, increase in the fluence decreased the polarisation resistance. A fluence of $10^{17} \mathrm{ion} \cdot \mathrm{cm}^{-2}$ decreased the polarisation resistance by $65 \%$, and fluences of $10^{15}$ and $10^{16}$ showed only marginal effect. Similarly, potentiodynamic polarisation results also suggested that low fluence of calcium-ion decreased the degradation rate by $38 \%$ and high fluence of zinc-ion increased the degradation rate by $61 \%$. All the post-polarized ion-implanted samples and the bare metal revealed phosphate and carbonate formation. However, the improved degradative behaviour in calcium-ion implanted samples can be due to a relatively better passivation, whereas the reduction in degradation resistance in zinc-ion implanted samples can be attributed to the micro-galvanic effect.
\end{abstract}

Keywords: magnesium; biomaterials; degradation; ion implantation

\section{Introduction}

Ion implantation is a versatile technique for surface engineering of metallic biomaterials. This technique has been widely used to augment or introduce desirable properties in metals. More specifically, ion implantation has been shown to improve the degradation resistance of metals such as titanium, aluminium and stainless steel under various environments [1-14]. Recently, ion-implantation studies have been carried out on magnesium and magnesium-based alloys for biodegradable implant applications. Since the rapid degradation of magnesium is a serious concern, ion implantation seems a promising technique to increase its potential for biodegradable implant use.

Elements such as zirconium, iron and aluminium have been ion implanted in magnesium and magnesium-based alloys, and their in vitro degradation behaviour has been studied [15-19]. Zhao et al. [15] studied the in vitro degradation and biocompatibility of zirconium-ion and oxygen-ion implantation in $\mathrm{Mg}-\mathrm{Ca}$ and $\mathrm{Mg}$-Sr alloys. They reported that a hydrophobic $\mathrm{ZrO}_{2}$ layer was formed and improved the cell and bacterial adhesion and degradation resistance. Jamesh et al. [16] conducted a similar study on ZK60 magnesium alloy and reported the beneficial effect of zirconium-ion and oxygen-ion implantation in terms of degradation resistance. They found calcium phosphate and zirconium phosphate formation on the implanted surface. The same group [17] also studied the in vitro degradation behaviour of zirconium-ion and nitrogen-ion implantation in a rare-earth containing 
magnesium alloy (WE43). They reported significant improvement in the degradation resistance, and attributed this to the formation of zirconium and nitrogen-rich layers and specific functional groups $\mathrm{ZrN}, \mathrm{ZrO}_{2}$ and $\mathrm{Y}_{2} \mathrm{O}_{3}$. Wu et al. [18] examined the influence of aluminium-ion implantation in AZ31 and AZ91 magnesium alloys' degradation behaviour. They reported a significant increase in degradation resistance as a result of the formation of an aluminium-rich oxide layer and aluminium-rich metal layers.

For biomedical applications, the biocompatibility of the implanted element is critical. Zinc is a biocompatible metal and has been used as an alloying element in magnesium for potential biodegradable implants [20,21]. Recently, there have been some works on zinc-ion implantation [22-24]. $\mathrm{Wu}$ et al. [22] examined the in vitro degradation of zinc-ion implantation in pure magnesium. The degradation resistance decreased with zinc-ion implantation at a fluence of $2.5 \times 10^{17} \mathrm{ion} \cdot \mathrm{cm}{ }^{-2}$, which was attributed to galvanic corrosion between the zinc-rich region and the magnesium matrix. Wan et al. [23] used a slightly lower fluence, i.e., $0.9 \times 10^{17} \mathrm{ion} \cdot \mathrm{cm}^{-2}$, for zinc-ion implantation in a magnesium-calcium alloy and congruently found that zinc-ion decreased the degradation resistance under in vitro conditions. However, they found that the surface hardness and elastic modulus of the alloy increased with zinc-ion implantation. Xu et al. [24] studied the combined effect of zinc-ion and aluminium-ion in pure magnesium (fluence: $3.6 \times 10^{17} \mathrm{ion} \cdot \mathrm{cm}^{-2}$ ). They first implanted zinc-ion and then carried out aluminium-ion implantation. They observed improved degradation resistance, which was attributed to the formation of a heterogeneous oxide layer and a $\beta-\mathrm{Mg}_{17} \mathrm{Al}_{12}$ phase.

The typical range of fluence for ion implantation in metals is $10^{15}-10^{18} \mathrm{ion} \cdot \mathrm{cm}^{-2}$. Generally speaking, fluences above this range will introduce defects and crystallographic dislocations [18,25], and those below this range will have very few observable effects [26]. Variation of fluence could have an influence on the degradation behaviour of the material. It should be noted that all work on zinc-ion implantation has been done at a relatively high fluence $\left(0.9 \times 10^{17}\right.$ to $3.6 \times 10^{17}$ ion $\left.\cdot \mathrm{cm}^{-2}\right)$. Hence, it is worthwhile to examine lower fluences of zinc-ion as well to see if the degradation resistance is affected, since zinc-containing magnesium alloys have shown improvements to degradation resistance [20,27].

Calcium is a biocompatible alkaline earth metal, which is a major component of bone and has many beneficial effects including osseointegration [28]. As alloying with calcium has been shown to improve the degradative resistance of magnesium [29-31], it would be interesting to see if calcium-ion implantation produces similar effects. Krupa et al. [32] reported enhanced degradation resistance in titanium after calcium-ion implantation at a fluence of $10^{-17} \mathrm{ion} \cdot \mathrm{cm}^{-2}$. Amorphization of the surface layer of titanium was observed when implanted with calcium-ion. To the authors' best knowledge, there has been no reported literature on calcium-ion implantation in magnesium-based materials.

In this study, pure magnesium was implanted with calcium-ion and zinc-ion at three different fluences and their in vitro degradation behaviours were evaluated using electrochemical techniques in simulated body fluid (SBF).

\section{Materials and Methods}

In this study, pure magnesium was implanted with calcium-ion and zinc-ion. The chemical composition of pure magnesium is given in Table 1. Prior to implantation, the samples were incrementally ground from 120 to 2500 grit $\mathrm{SiC}$ paper and then polished with diamond paste. After polishing, the samples were ultrasonically cleaned in acetone and then in ethanol and dried. Ion implantation was performed at Australian Nuclear Science \& Technology Organisation (ANSTO) using an in-house designed equipment capable to mass-analyse the ion beam, produced by a penning ion source. Implantation was done at room temperature on one side of the sample with an accelerating ion energy of $15 \mathrm{keV}$ and ion-beam current density of $2 \mu \mathrm{A} / \mathrm{cm}^{2}$. Three fluences were used for the implantation of ion, i.e., $10^{15}, 10^{16}$ and $10^{17} \mathrm{ion} \cdot \mathrm{cm}^{-2}$. The vacuum in the target chamber was $10^{-5} \mathrm{~Pa}$. The samples ion implanted with calcium at $10^{15}, 10^{16}$ and $10^{17} \mathrm{ion} \cdot \mathrm{cm}^{-2}$ fluences are named as Ca-15, Ca-16 and Ca-17, respectively. Similarly, samples ion implanted with zinc at $10^{15}, 10^{16}$ and $10^{17}$ ion $\cdot \mathrm{cm}^{-2}$ fluences are named as Zn-15, Zn-16 and Zn-17, respectively. 
Table 1. Chemical composition of magnesium.

\begin{tabular}{ccccccccc}
\hline Element & Zn & Ca & Fe & Cu & Al & Mn & Si & Mg \\
\hline Weight $\%$ & 0.008 & 0.003 & 0.004 & 0.001 & 0.007 & 0.002 & 0.01 & Bal. \\
\hline
\end{tabular}

In vitro degradation tests were carried out in simulated body fluid (SBF) maintained at a physiological $\mathrm{pH}$ value of 7.4 and temperature of $37 \pm 0.5^{\circ} \mathrm{C}$. The chemical composition of SBF is given in Table 2. Electrochemical tests were conducted using a potentiostat/frequency response analyser (Model: ACM Gill AC, ACM Instruments, Cumbria, UK) and a three electrode system with the sample ( $0.785 \mathrm{~cm}^{2}$ exposed area) as the working electrode, an $\mathrm{Ag} / \mathrm{AgCl}$ reference electrode and a platinum counter electrode. Electrochemical impedance spectroscopy (EIS) tests were carried out with an AC amplitude of $5 \mathrm{mV}$ over the frequency range of $10^{5} \mathrm{~Hz}$ to $10^{-2} \mathrm{~Hz}$. The EIS spectra were modelled using ZSimpWin V. 3.21 software (Ametek Scientific Instruments, Pittsburgh, PA, USA). Potentiodynamic polarisation was performed at a scan rate of $0.5 \mathrm{mV} / \mathrm{s}$. Prior to the electrochemical testing, the samples were immersed in the SBF for $2 \mathrm{~h}$. A digital macroscope was used to analyse the degradation morphology of the post-polarised samples. Fourier transform infrared (FTIR) spectroscopy analysis (Model: Perkin Elmer spectrum 100 FTIR spectrometer, Perkin Elmer, Houston, TX, USA) was done to identify the degradation products.

Table 2. Chemical composition of simulated body fluid (SBF).

\begin{tabular}{cc}
\hline Reagent & Amount \\
\hline $\mathrm{NaCl}(\mathrm{g} / \mathrm{L})$ & 8.036 \\
$\mathrm{NaHCO}_{3}(\mathrm{~g} / \mathrm{L})$ & 0.352 \\
$\mathrm{KCl}(\mathrm{g} / \mathrm{L})$ & 0.225 \\
$\mathrm{~K}_{2} \mathrm{HPO}_{4} \cdot 3 \mathrm{H}_{2} \mathrm{O}(\mathrm{g} / \mathrm{L})$ & 0.230 \\
$\mathrm{MgCl}_{2} \cdot 6 \mathrm{H}_{2} \mathrm{O}(\mathrm{g} / \mathrm{L})$ & 0.311 \\
$1.0 \mathrm{M} \mathrm{HCl}^{(\mathrm{mL} / \mathrm{L})}$ & 40.0 \\
$\mathrm{CaCl}_{2}(\mathrm{~g} / \mathrm{L})$ & 0.293 \\
$\mathrm{Na}_{2} \mathrm{SO}_{4}(\mathrm{~g} / \mathrm{L})$ & 0.072 \\
$\left.\mathrm{TRIS} \mathrm{Buffer}^{\mathrm{T}} / \mathrm{L}\right)$ & 6.063 \\
\hline
\end{tabular}

\section{Results}

The Rutherford backscattering (RBS) surface characterisation data of calcium-ion and zinc-ion implanted samples are presented in Figure 1a,b, respectively. Characteristic calcium and zinc backscattered peaks for respective samples are shown at channel numbers (equivalent to energy) $\sim 330-340$ and $\sim 380-410$, respectively, indicating that the desired ions were successfully implanted into the magnesium substrate, and, as expected, the concentration of the implanted ions increased with the increase in the fluence. Depth profiling revealed that the incident calcium and zinc appear around $30 \mathrm{~nm}$ beneath the surface. Additionally, peaks at channel number 175 in all the samples indicate the presence of oxygen. Depth profiling reveals oxygen presence from the top layer down to a depth of $\sim 75 \mathrm{~nm}$ in all the samples. The oxygen atoms above the implanted layers are likely constituent of the passive $\mathrm{MgO} / \mathrm{Mg}(\mathrm{OH})_{2}$ film normally found on the surface of magnesium. Thus, the incident calcium or zinc atoms are implanted within the passive $\mathrm{MgO} / \mathrm{Mg}(\mathrm{OH})_{2}$ layer. However, given that this passive layer is typically only several nanometres thick without augmentation [33], it is also possible that the ion implantation process has added oxygen to the oxide layer from impurities in the source material. 

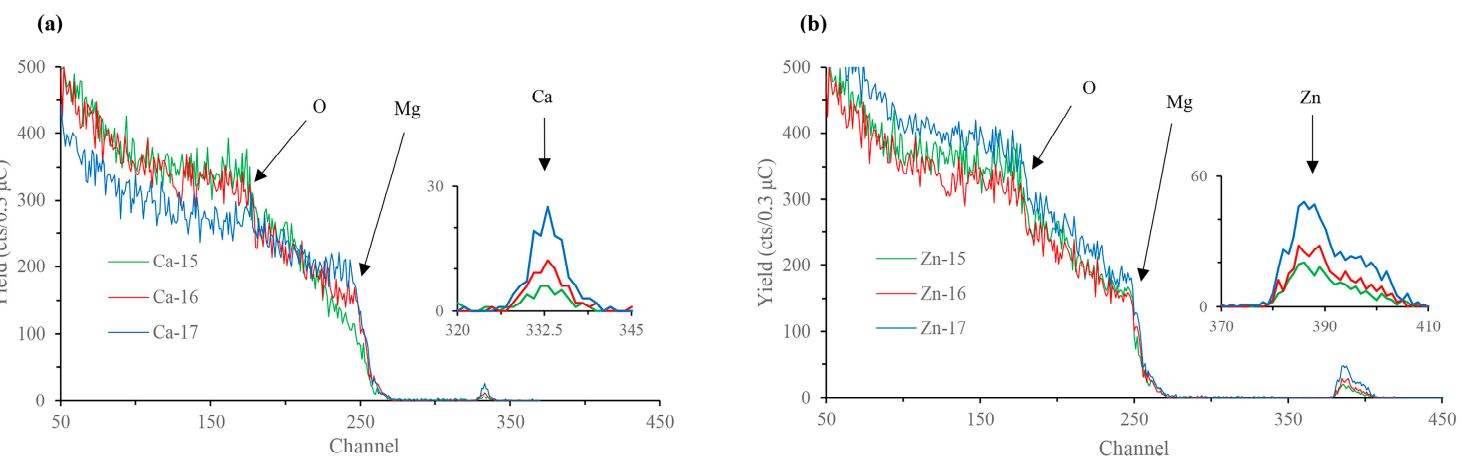

Figure 1. Rutherford backscattering (RBS) spectra of: (a) Ca-ion; and (b) Zn-ion implanted magnesium.

The Nyquist plots of the calcium-ion implanted magnesium and the equivalent circuit (EC) used to model EIS spectra are shown in Figure 2a, and the obtained EC results are shown in Table 3. All the calcium-ion implanted samples showed two capacitive loops, as observed for the bare metal. The high frequency capacitive loop corresponds to charge transfer resistance and double layer capacitance, and the mid-frequency capacitive loop is indicative of the relaxation of mass transport through the layer formed due to degradation [34]. The EC model used in this study has been used for both bare and surface engineered magnesium [35-37], where $R_{\mathrm{s}}$ represents the solution resistance, $R_{\mathrm{ct}}$ and $C_{\mathrm{dl}}$ are the charge transfer resistance and double layer capacitance, respectively, and $R_{\mathrm{f}}$ and $\mathrm{C}_{\mathrm{f}}$ represent the film effects [36]. The polarisation resistances $\left(R_{\mathrm{p}}\right)$, which were calculated by adding $R_{\mathrm{f}}$ and $R_{\mathrm{ct}}$ [38], are shown in Figure $2 \mathrm{~b}$. The $R_{\mathrm{p}}$ of Ca-15 was $24 \%$ higher than the bare metal and, interestingly, those of higher fluences did not show any significant improvement. In addition, a low frequency inductive loop can be noted for the bare metal and all the calcium-ion implanted samples. This behaviour is an indication of localized degradation (pitting) susceptibility of the samples [39]. The Nyquist plots of the zinc-ion implanted magnesium and the equivalent circuit (EC) used to model EIS spectra are shown in Figure 2c, and the obtained EC results are shown in Table 3. Similar to the calcium-ion implanted samples, the zinc-ion implanted samples each showed two capacitive loops and an inductive loop. However, it was observed that the $R_{\mathrm{p}}$ reduced significantly when the zinc-ion fluence was high, i.e., $\mathrm{Zn}-17$ sample showed $65 \%$ lower $R_{\mathrm{p}}$ than the bare metal (Figure $2 \mathrm{~d}$ ).

Figure $3 \mathrm{a}, \mathrm{b}$ and Table 4 show the potentiodynamic polarisation curves and the corresponding electrochemical results of the ion implanted samples, respectively. The corrosion potential $\left(E_{\text {corr }}\right)$ of calcium-ion implanted samples did not show any significant change from that of the bare metal. The cathodic current decreased for Ca-15 and Ca-16 samples, whereas for the Ca-17 sample it was similar to the base metal. In the anodic part, a passive-like behaviour was observed for the base metal and the calcium-ion implanted samples. It should be noted that the passive currents for calcium-ion implanted samples were lower than the base material, which suggests that calcium-ion has contributed to better passivation behaviour. Ca-15 showed the highest protection among the calcium-ion implanted samples, and also the passive potential range $\left(E_{\text {pass }}\right)$ for Ca-15 was higher than the bare metal. The breakdown potentials $\left(E_{\mathrm{bd}}\right)$ of the calcium-ion implantation samples were similar to the bare metal. The breakdown potentials at around $-1.4 \mathrm{~V}$ for all samples suggest that the passive film contains magnesium hydroxide [40]. However, in calcium-ion implanted samples, the film may contain more calcium-based products and hence exhibited better protection. The corrosion current $\left(i_{\text {corr }}\right)$, which was calculated based on the cathodic curves suggests that the $i_{\text {corr }}$ decreased with calcium-ion implantation. The $i_{\text {corr }}$ of Ca- 15 was $38 \%$ lower, whereas Ca-16 and Ca-17 showed only $14 \%$ and $8 \%$ reduction, respectively, as compared to the bare metal. 

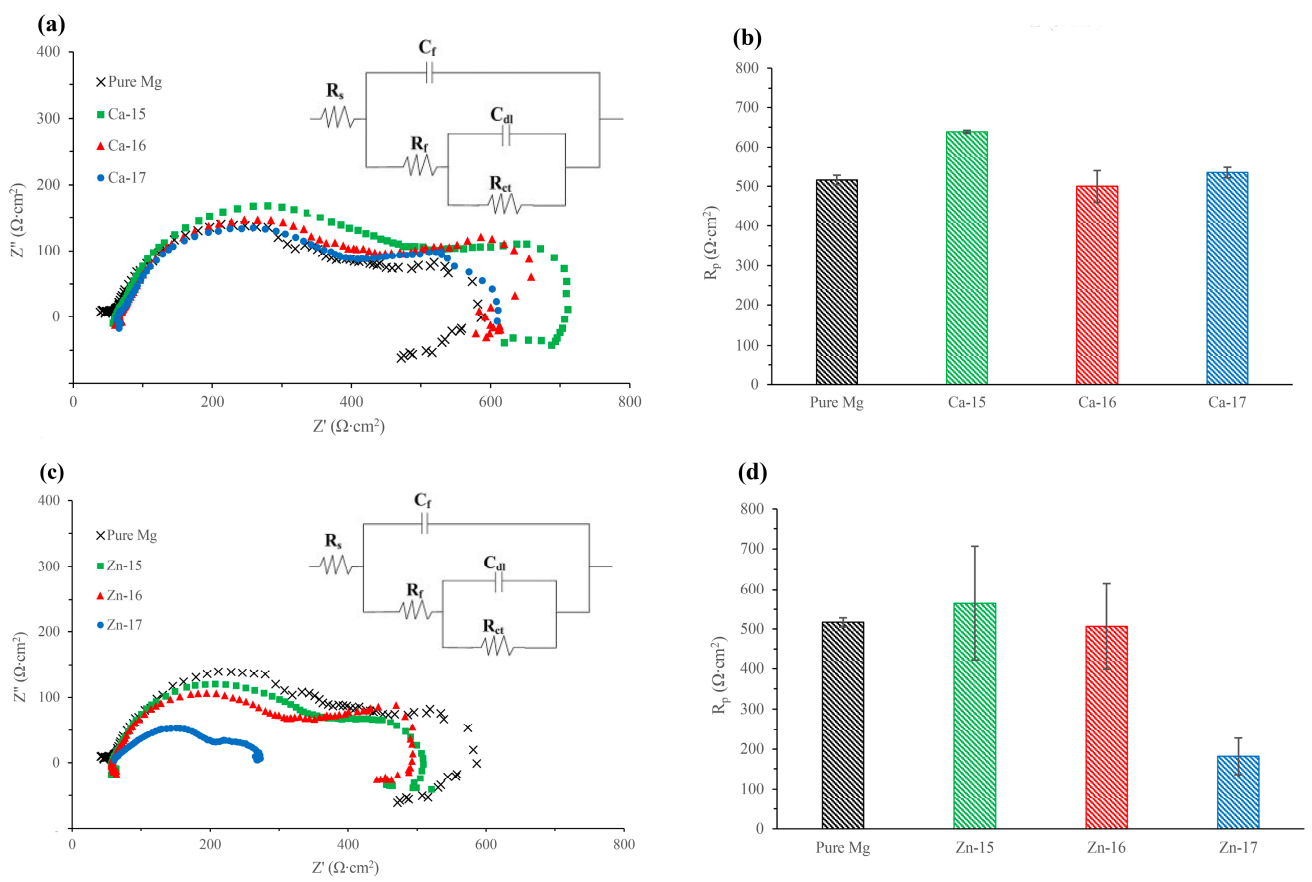

Figure 2. Ca-ion implanted magnesium in SBF: (a) Nyquist plot and equivalent circuit; and (b) polarisation resistance. Zn-ion implanted magnesium in SBF: (c) Nyquist plot and equivalent circuit; and $(\mathbf{d})$ polarisation resistance.

Table 3. Electrochemical impedance spectroscopy (EIS) results of Ca-ion and Zn-ion implanted magnesium in SBF.

\begin{tabular}{|c|c|c|c|c|c|c|}
\hline Sample & $\begin{array}{c}C_{\mathrm{dl} l}\left(\Omega^{-1} \cdot \mathrm{cm}^{-2} \cdot \mathrm{s}^{-n}\right) \\
\left(\times 10^{-3}\right)\end{array}$ & $n-\mathrm{C}_{\mathrm{dl}}$ & $R_{\mathrm{t}}\left(\Omega \cdot \mathrm{cm}^{2}\right)$ & $\begin{array}{c}C_{\mathrm{f}}\left(\Omega^{-1} \cdot \mathrm{cm}^{-2} \cdot \mathrm{s}^{-n}\right) \\
\left(\times 10^{-5}\right)\end{array}$ & $n-\mathrm{C}_{\mathrm{f}}$ & $R_{\mathrm{f}}\left(\Omega \cdot \mathrm{cm}^{2}\right)$ \\
\hline Pure Mg & $1.05 \pm 1.72$ & 0.74 & $94.93 \pm 59.68$ & $11.25 \pm 15.62$ & 0.69 & $429.80 \pm 89.75$ \\
\hline $\mathrm{Ca}-15$ & $2.61 \pm 0.16$ & 0.99 & $164.65 \pm 33.59$ & $5.28 \pm 0.19$ & 0.80 & $466.80 \pm 34.51$ \\
\hline Ca-16 & $2.95 \pm 0.05$ & 0.92 & $173.65 \pm 60.25$ & $5.32 \pm 0.20$ & 0.79 & $357.71 \pm 47.80$ \\
\hline $\mathrm{Ca}-17$ & $3.07 \pm 0.30$ & 0.99 & $147.30 \pm 24.46$ & $5.64 \pm 0.23$ & 0.78 & $366.62 \pm 4.38$ \\
\hline $\mathrm{Zn}-15$ & $3.10 \pm 0.16$ & 0.98 & $130.80 \pm 10.61$ & $5.53 \pm 0.61$ & 0.79 & $404.95 \pm 133.14$ \\
\hline $\mathrm{Zn}-16$ & $2.53 \pm 0.45$ & 0.95 & $177.05 \pm 31.18$ & $5.22 \pm 0.42$ & 0.80 & $315.90 \pm 61.37$ \\
\hline $\mathrm{Zn}-17$ & $2.73 \pm 3.72$ & 0.84 & $80.46 \pm 50.83$ & $9.02 \pm 8.23$ & 0.66 & $98.62 \pm 97.34$ \\
\hline
\end{tabular}

Note: All experiments were conducted in duplicates; standard deviations are given.

Table 4. Electrochemical results of Ca-ion and Zn-ion implanted magnesium in SBF.

\begin{tabular}{ccccc}
\hline Sample & $\boldsymbol{E}_{\text {corr }}(\mathbf{m V} \mathbf{v} \mathbf{A g} / \mathbf{A g C l})$ & $\boldsymbol{i}_{\text {corr }}\left(\boldsymbol{\mu} \mathbf{A} / \mathbf{c m}^{\mathbf{2}}\right)$ & $\boldsymbol{E}_{\mathbf{b d}}(\mathbf{m V} \mathbf{v ~ A g} / \mathbf{A g C l})$ & $E_{\text {pass }}(\mathbf{m V})$ \\
\hline Pure Mg & $-1820 \pm 24.27$ & $161.66 \pm 5.50$ & $-1418 \pm 18.50$ & $401 \pm 4.72$ \\
Ca-15 & $-1825 \pm 16.26$ & $100 \pm 0.00$ & $-1384 \pm 16.97$ & $441 \pm 33.23$ \\
Ca-16 & $-1817 \pm 4.24$ & $138 \pm 1.41$ & $-1443 \pm 19.79$ & $374 \pm 24.04$ \\
Ca-17 & $-1811 \pm 12.72$ & $148 \pm 36.77$ & $-1437 \pm 15.55$ & $374 \pm 2.82$ \\
Zn-15 & $-1833 \pm 9.89$ & $140.5 \pm 57.27$ & $-1399 \pm 20.50$ & $433 \pm 10.61$ \\
Zn-16 & $-1809 \pm 15.55$ & $171 \pm 14.14$ & $-1411 \pm 16.97$ & $398 \pm 32.53$ \\
Zn-17 & $-1583 \pm 0.00$ & $259.5 \pm 13.43$ & $-1440 \pm 6.36$ & $142.5 \pm 6.36$ \\
\hline
\end{tabular}

Note: All experiments were conducted in duplicates; standard deviations are given.

In the case of zinc-ion implanted samples, the $E_{\text {corr }}$ of $\mathrm{Zn}-15$ and $\mathrm{Zn}-16$ were not significantly different to that of bare metal, but Zn-17 (high fluence) showed a noble potential shift of $237 \mathrm{mV}$. The cathodic current for Zn-16 was similar to bare metal, and Zn-15 was marginally lower and $\mathrm{Zn}-17$ was significantly lower. A passive-like behaviour and $E_{\mathrm{bd}}$ were observed in all the zinc ion implanted samples, but the $E_{\text {pass }}$ was much lower for Zn-17. The $i_{\text {corr }}$ data suggest that high-fluence zinc implantation is detrimental, as $\mathrm{Zn}-17$ exhibited $61 \%$ higher $i_{\text {corr }}$ than the bare metal. Figure $3 \mathrm{c}$ 
compares the degradation rate of calcium-implanted and zinc-implanted samples. The degradation rate has decreased with Ca-15. However, with higher fluence of calcium, the difference in the degradation rate became smaller. In the case of zinc, the degradation rate increased with increase in zinc-ion fluence.
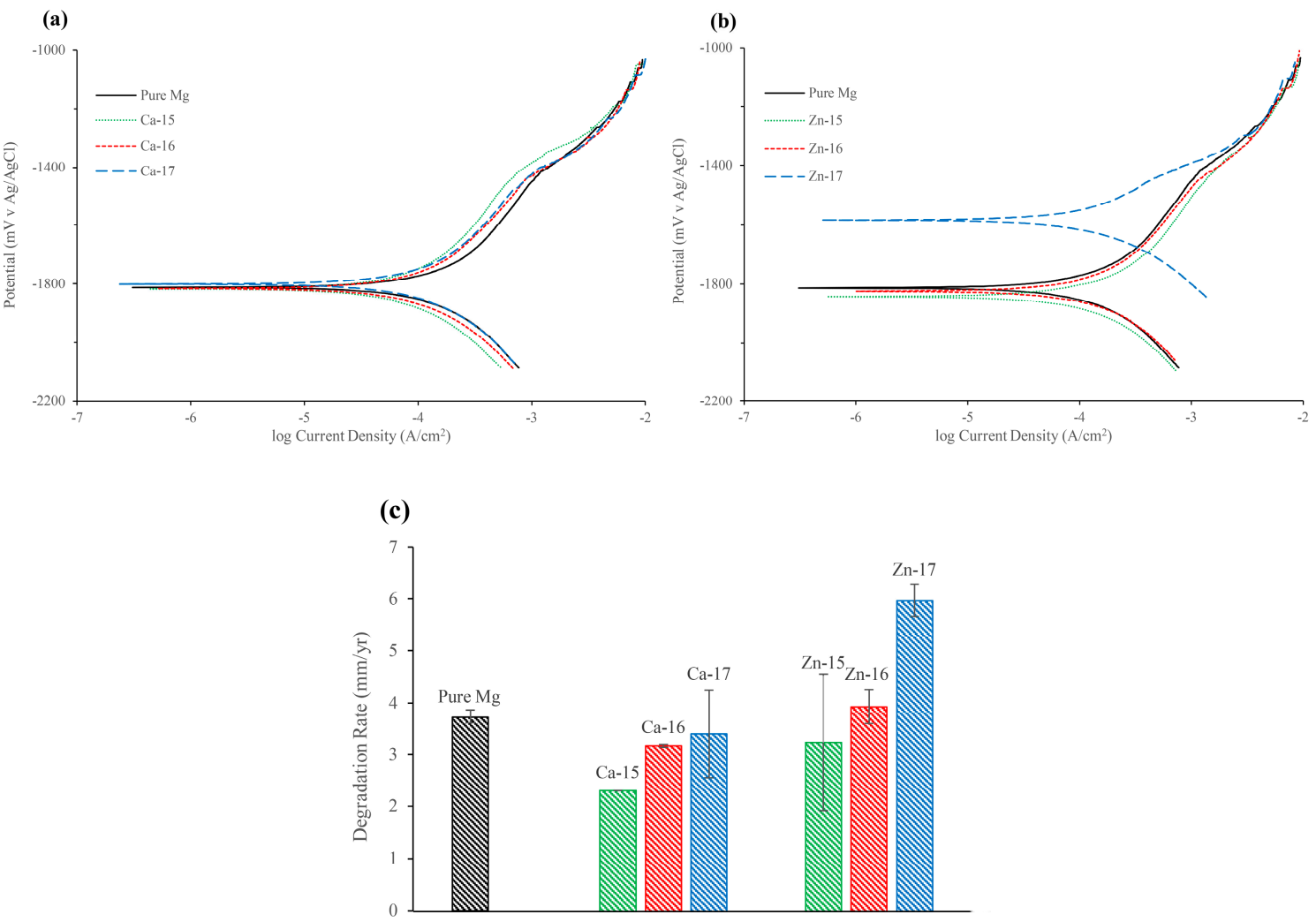

Figure 3. Potentiodynamic polarisation plots of: (a) Ca-ion; and (b) Zn-ion implanted magnesium in SBF; and (c) degradation rate of Ca-ion and Zn-ion implanted magnesium in SBF.

The macrographs of the post-polarised samples are shown in Figure 4. Localized degradation can be seen in all the samples, since they were polarised above breakdown potential. However, the intensity of the degradation attack is different. In the case of Ca-15, the degradation was much lower as compared to the bare metal, which agrees with the electrochemical results. Additionally, $\mathrm{Zn}-17$ exhibited the highest degradation, as is seen by the intensity of corroded pits. To examine the difference in the product formation during degradation, FTIR analysis was done and the spectra are shown in Figure 5a,b. The prominent bands around $1050 \mathrm{~cm}^{-1}$ correspond to phosphate groups [41], while those around $1400 \mathrm{~cm}^{-1}$ are indicative of carbonate groups [42]. None of the implanted samples show appreciable formation of distinct degradation products when compared to the bare metal. 


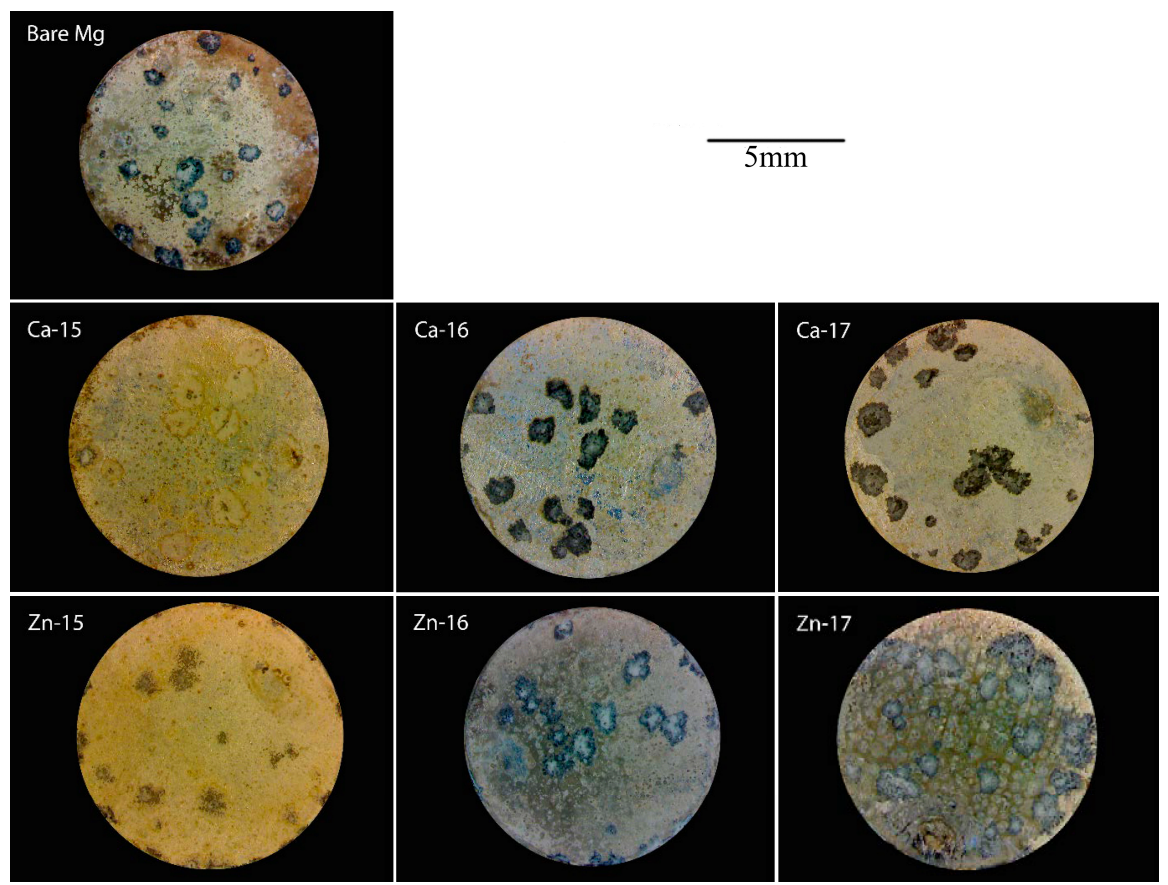

Figure 4. Macrographs of Ca-ion and Zn-ion implanted magnesium after potentiodynamic polarisation in SBF.

(a)

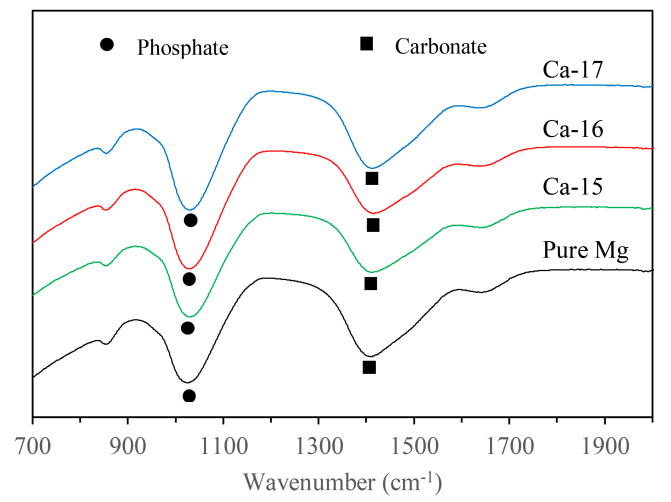

(b)

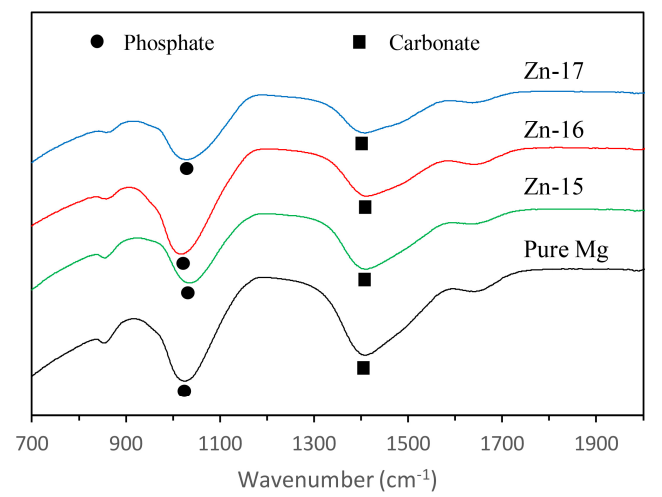

Figure 5. Fourier transform infrared (FTIR) spectra of: (a) Ca-ion; and (b) Zn-ion implanted magnesium after potentiodynamic polarisation in SBF.

\section{Discussion}

Calcium-ion implantation at a fluence of $10^{15} \mathrm{ion} \cdot \mathrm{cm}^{-2}$ slightly inhibited the degradation, however, for biodegradable implant applications, the degradation resistance should be further improved [43]. Interestingly, calcium-ion implantation at higher fluences $\left(10^{16}\right.$ and $10^{17}$ ion $\left.\cdot \mathrm{cm}^{-2}\right)$ did not show any appreciable improvement in the degradation resistance. Implantation at these higher fluences may have introduced defects and thereby affected the passivation. On the other hand, zinc-ion implantation aggravated the degradation. The higher degradation rate can be attributed to micro-galvanic degradation between the magnesium and the more electrochemically noble zinc. The anodic sites of micro-galvanic degradation, in this case, magnesium-rich areas, exhibited localised degradation. It is interesting to note that alloying zinc to magnesium has shown improvement in the degradation resistance [20,44,45]. Koç et al. [20] reported an increase in degradation resistance in zinc-containing magnesium alloys and attributed this to grain size refinement. However, ion-implantation has no effect on the grain size. Cai et al. [44] and Koç et al. [20] further attributed the 
improved degradation resistance in zinc-containing alloys to uniform distribution of zinc assisting in the passivation, however when added in small amounts (i.e., less than or equal to $5 \mathrm{wt} \%$ ). In the case of ion-implantation, densely-populated zinc appears to be detrimental.

Overall, the study suggests that ion implantation of zinc is certainly detrimental for the degradation resistance of magnesium. Calcium-ion implantation, especially at low fluence, improves the degradation resistance of magnesium, but it is not high enough to be used in biodegradable implant applications. The dissolution tendency of the base material may have an influence on the degradation performance of ion implanted material. A relatively high degradation resistant magnesium alloy implanted with calcium-ion may have a synergistic effect. It is worthwhile to carry out calcium-ion implantation on magnesium alloys and understand its influence.

\section{Conclusions}

Magnesium was implanted with calcium-ions and zinc-ions at fluences of $10^{15}, 10^{16}$ and $10^{17}$ ion $\cdot \mathrm{cm}^{-2}$ and their in vitro degradation resistances were evaluated. Calcium-ion implantation at $10^{16}$ and $10^{17} \mathrm{ion} \cdot \mathrm{cm}^{-2}$ had no effect, and that at $10^{15}$ ion $\mathrm{cm}^{-2}$ showed a marginal, however insufficient, increase in the degradation resistance. Zinc-ion implantation at $10^{15}$ and $10^{16} \mathrm{ion} \cdot \mathrm{cm}^{-2}$ had no effect, and, in fact, that at $10^{17}$ ion $\cdot \mathrm{cm}^{-2}$ decreased degradation resistance significantly. Calcium-ion or zinc-ion implantation is not promising for enhancing the biodegradation resistance of magnesium for bone fixation devices.

Acknowledgments: The authors would like to thank The Australian Institute of Nuclear Science and Engineering (AINSE) for the financial support to carry out ion implantation work at Australian Nuclear Science \& Technology Organisation (ANSTO) in Sydney (AINSE Award No. ALNGRA14545). The authors acknowledge the financial support from the Australian Government for the Centre for Accelerator Science at ANSTO through the National Collaborative Research Infrastructure Strategy (NCRIS).

Author Contributions: B.K.M. and M.I. conceived and designed the experiments; S.S. and M.I. performed the experiments; B.K.M., S.S. and M.I. analyzed the data; and B.K.M. and S.S. wrote the paper.

Conflicts of Interest: The authors declare no conflict of interest.

\section{References}

1. Hartwig, A.; Decker, M.; Klein, O.; Karl, H. Stoichiometric titanium dioxide ion implantation in aisi 304 stainless steel for corrosion protection. Nucl. Instrum. Methods Phys. Res. Sect. B Beam Interact. Mater. Atoms 2015, 365, 94-99. [CrossRef]

2. Guo, Z.; Pang, X.; Yan, Y.; Gao, K.; Volinsky, A.A.; Zhang, T.-Y. Cocrmo alloy for orthopedic implant application enhanced corrosion and tribocorrosion properties by nitrogen ion implantation. Appl. Surf. Sci. 2015, 347, 23-34. [CrossRef]

3. Huang, H.-H.; Huang, H.-M.; Lin, M.-C.; Zhang, W.; Sun, Y.-S.; Kai, W.; Liaw, P.K. Enhancing the bio-corrosion resistance of ni-free zrcufeal bulk metallic glass through nitrogen plasma immersion ion implantation. J. Alloys Compd. 2014, 615 (Suppl. 1), S660-S665. [CrossRef]

4. Escalada, L.; Lutz, J.; Brühl, S.P.; Fazio, M.; Márquez, A.; Mändl, S.; Manova, D.; Simison, S.N. Microstructure and corrosion behavior of aisi 3161 duplex treated by means of ion nitriding and plasma based ion implantation and deposition. Surf. Coat. Technol. 2013, 223, 41-46. [CrossRef]

5. Feng, K.; Wang, Y.; Li, Z.; Chu, P.K. Characterization of carbon ion implantation induced graded microstructure and phase transformation in stainless steel. Mater. Charact. 2015, 106, 11-19. [CrossRef]

6. Hongxi, L.; Qian, X.; Xiaowei, Z.; Chuanqi, W.; Baoyin, T. Wear and corrosion behaviors of ti6al4v alloy biomedical materials by silver plasma immersion ion implantation process. Thin Solid Films 2012, 521, 89-93. [CrossRef]

7. Zhang, M.; Ma, S.; Xu, K.; Chu, P.K. Corrosion resistance of praseodymium-ion-implanted tin coatings in blood and cytocompatibility with vascular endothelial cells. Vacuum 2015, 117, 73-80. [CrossRef]

8. Grayeli-Korpi, A.-R.; Savaloni, H. Effect of nitrogen ion implantation on corrosion inhibition of nickel coated 316 stainless steel and correlation with nano-structure. Appl. Surf. Sci. 2012, 258, 9982-9988. [CrossRef]

9. Zhang, E.; Chen, Y.; Tang, Y. Effect of copper ion implantation on corrosion morphology and corrosion behavior of $\mathrm{LaFe}_{11.6} \mathrm{Si}_{1.4}$ alloy. J. Rare Earths 2012, 30, 269-273. [CrossRef] 
10. Feng, K.; Cai, X.; Li, Z.; Chu, P.K. Improved corrosion resistance of stainless steel 3161 by ti ion implantation. Mater. Lett. 2012, 68, 450-452. [CrossRef]

11. Williams, J.M.; Gonzales, A.; Quintana, J.; Lee, I.S.; Buchanan, R.A.; Burns, F.C.; Culbertson, R.J.; Levy, M.; Treglio, J.R. Ion implantation for corrosion inhibition of aluminum alloys in saline media. Nucl. Instrum. Methods Phys. Res. Sect. B 1991, 59-60, 845-850. [CrossRef]

12. Abreu, C.M.; Cristóbal, M.J.; Figueroa, R.; Pena, G. Influence of molybdenum ion implantation on the localized corrosion resistance of a high strength aluminium alloy. Corros. Sci. 2012, 54, 143-152. [CrossRef]

13. Liu, Y.Z.; Zu, X.T.; Wang, L.; Qiu, S.Y. Role of aluminum ion implantation on microstructure, microhardness and corrosion properties of titanium alloy. Vacuum 2008, 83, 444-447. [CrossRef]

14. Ali, N.; Fulazzaky, M.A.; Mustapa, M.S.; Ghazali, M.I.; Ridha, M.; Sujitno, T. Assessment of fatigue and corrosion fatigue behaviours of the nitrogen ion implanted cpti. Int. J. Fatigue 2014, 61, 184-190. [CrossRef]

15. Zhao, Y.; Jamesh, M.I.; Li, W.K.; Wu, G.; Wang, C.; Zheng, Y.; Yeung, K.W.K.; Chu, P.K. Enhanced antimicrobial properties, cytocompatibility, and corrosion resistance of plasma-modified biodegradable magnesium alloys. Acta Biomater. 2014, 10, 544-556. [CrossRef] [PubMed]

16. Jamesh, M.I.; Wu, G.; Zhao, Y.; McKenzie, D.R.; Bilek, M.M.M.; Chu, P.K. Effects of zirconium and oxygen plasma ion implantation on the corrosion behavior of ZK60 Mg alloy in simulated body fluids. Corros. Sci. 2014, 82, 7-26. [CrossRef]

17. Jamesh, M.I.; Wu, G.; Zhao, Y.; Jin, W.; McKenzie, D.R.; Bilek, M.M.M.; Chu, P.K. Effects of zirconium and nitrogen plasma immersion ion implantation on the electrochemical corrosion behavior of $\mathrm{Mg}-\mathrm{Y}-\mathrm{Re}$ alloy in simulated body fluid and cell culture medium. Corros. Sci. 2014, 86, 239-251. [CrossRef]

18. Wu, G.; Xu, R.; Feng, K.; Wu, S.; Wu, Z.; Sun, G.; Zheng, G.; Li, G.; Chu, P.K. Retardation of surface corrosion of biodegradable magnesium-based materials by aluminum ion implantation. Appl. Surf. Sci. 2012, 258, 7651-7657. [CrossRef]

19. Zheng, Y.; Li, Y.; Chen, J.; Zou, Z. Surface characteristics and corrosion resistance of biodegradable magnesium alloy ZK60 modified by Fe ion implantation and deposition. Prog. Nat. Sci. Mater. Int. 2014, 24, 547-553. [CrossRef]

20. Koç, E.; Kannan, M.B.; Ünal, M.; Candan, E. Influence of zinc on the microstructure, mechanical properties and in vitro corrosion behavior of magnesium-zinc binary alloys. J. Alloys Compd. 2015, 648, 291-296. [CrossRef]

21. Kubásek, J.; Vojtěch, D. Structural characteristics and corrosion behavior of biodegradable Mg-Zn, Mg-Zn-Gd alloys. J. Mater. Sci. Mater. Med. 2013, 24, 1615-1626. [CrossRef] [PubMed]

22. Wu, G.; Gong, L.; Feng, K.; Wu, S.; Zhao, Y.; Chu, P.K. Rapid degradation of biomedical magnesium induced by zinc ion implantation. Mater. Lett. 2011, 65, 661-663. [CrossRef]

23. Wan, Y.Z.; Xiong, G.Y.; Luo, H.L.; He, F.; Huang, Y.; Wang, Y.L. Influence of zinc ion implantation on surface nanomechanical performance and corrosion resistance of biomedical magnesium-calcium alloys. Appl. Surf. Sci. 2008, 254, 5514-5516. [CrossRef]

24. Xu, R.; Yang, X.; Suen, K.W.; Wu, G.; Li, P.; Chu, P.K. Improved corrosion resistance on biodegradable magnesium by zinc and aluminum ion implantation. Appl. Surf. Sci. 2012, 263, 608-612. [CrossRef]

25. Myasnikov, A.M.; Gerasimenko, N.N. Chapter 8 ion implantation and thermal annealing of III-V compound semiconducting systems: Some problems of III-V narrow gap semiconductors. In Semiconductors and Semimetals; Constantinos, C., Gérard, G., Eds.; Elsevier: Amsterdam, The Netherlands, 1997; Volume 46, pp. 257-293.

26. Yang, H.; Zhang, S.; Yu, D.; Li, K.; Hu, Q.; Yang, Y.; Zhang, K.; Li, H. Corrosion resistance and magnetostrictive properties of $\left(\mathrm{Tb}_{0.3} \mathrm{Dy}_{0.7}\right) \mathrm{Fe}_{2}$ alloy modified by nitrogen ion implantation. J. Rare Earths 2015, 33, 629-632. [CrossRef]

27. Song, Y.; Han, E.-H.; Dong, K.; Shan, D.; Yim, C.D.; You, B.S. Effect of hydrogen on the corrosion behavior of the Mg-xZn alloys. J. Magnes. Alloys 2014, 2, 208-213. [CrossRef]

28. Xu, L.; Pan, F.; Yu, G.; Yang, L.; Zhang, E.; Yang, K. In vitro and in vivo evaluation of the surface bioactivity of a calcium phosphate coated magnesium alloy. Biomaterials 2009, 30, 1512-1523. [CrossRef] [PubMed]

29. Rosalbino, F.; De Negri, S.; Saccone, A.; Angelini, E.; Delfino, S. Bio-corrosion characterization of Mg-Zn- $x$ ( $x=\mathrm{Ca}, \mathrm{Mn}, \mathrm{Si}$ ) alloys for biomedical applications. J. Mater. Sci. Mater. Med. 2010, 21, 1091-1098. [CrossRef] [PubMed] 
30. Harandi, S.E.; Mirshahi, M.; Koleini, S.; Idris, M.H.; Jafari, H.; Kadir, M.R.A. Effect of calcium content on the microstructure, hardness and in-vitro corrosion behavior of biodegradable Mg-Ca binary alloy. Mater. Res. 2013, 16, 11-18. [CrossRef]

31. Kim, K.H.; Nam, N.D.; Kim, J.G.; Shin, K.S.; Jung, H.C. Effect of calcium addition on the corrosion behavior of Mg-5Al alloy. Intermetallics 2011, 19, 1831-1838. [CrossRef]

32. Krupa, D.; Baszkiewicz, J.; Kozubowski, J.A.; Barcz, A.; Sobczak, J.W.; Biliński, A.; Lewandowska-Szumieł, M.; Rajchel, B. Effect of calcium-ion implantation on the corrosion resistance and biocompatibility of titanium. Biomaterials 2001, 22, 2139-2151. [CrossRef]

33. Feliu, S., Jr.; Galván, J.; Pardo, A.; Merino, M.; Arrabal, R. Native air-formed oxide film and its effect on magnesium alloys corrosion. Open Corros. J. 2010, 3, 80-91.

34. Zucchi, F.; Grassi, V.; Frignani, A.; Monticelli, C.; Trabanelli, G. Electrochemical behaviour of a magnesium alloy containing rare earth elements. J. Appl. Electrochem. 2006, 36, 195-204. [CrossRef]

35. Duan, H.; Yan, C.; Wang, F. Effect of electrolyte additives on performance of plasma electrolytic oxidation films formed on magnesium alloy AZ91D. Electrochim. Acta 2007, 52, 3785-3793. [CrossRef]

36. Alabbasi, A.; Bobby Kannan, M.; Walter, R.; Störmer, M.; Blawert, C. Performance of pulsed constant current silicate-based peo coating on pure magnesium in simulated body fluid. Mater. Lett. 2013, 106, 18-21. [CrossRef]

37. Walter, R.; Bobby Kannan, M. In-vitro degradation behaviour of we54 magnesium alloy in simulated body fluid. Mater. Lett. 2011, 65, 748-750. [CrossRef]

38. Jin, S.; Amira, S.; Ghali, E. Electrochemical impedance spectroscopy evaluation of the corrosion behavior of die cast and thixocast AXJ530 magnesium alloy in chloride solution. Adv. Eng. Mater. 2007, 9, 75-83. [CrossRef]

39. Virtanen, S.; Schmuki, P.; Frankel, G.S.; Division, E.S.C.; Meeting, E.S. Critical Factors in Localized Corrosion IV: A Symposium in Honor of the 65th Birthday of Hans Böhni: Proceedings of the International Symposium; Electrochemical Society: Pennington, NJ, USA, 2003.

40. Bobby Kannan, M.; Singh, R.K.R. A mechanistic study of in vitro degradation of magnesium alloy using electrochemical techniques. J. Biomed. Mater. Res. Part A 2010, 93A, 1050-1055.

41. Pramatarova, L.; Pecheva, E.; Presker, R.; Pham, M.T.; Maitz, M.F.; Stutzmann, M. Hydroxyapatite growth induced by native extracellular matrix deposition on solid surfaces. Eur. Cells Mater. 2005, 9, 9-12. [CrossRef]

42. Agha, N.A.; Feyerabend, F.; Mihailova, B.; Heidrich, S.; Bismayer, U.; Willumeit-Römer, R. Magnesium degradation influenced by buffering salts in concentrations typical of in vitro and in vivo models. Mater. Sci. Eng. C 2016, 58, 817-825. [CrossRef] [PubMed]

43. Mohanty, M.; Baby, S.; Menon, K.V. Spinal fixation device: A 6-year postimplantation study. J. Biomater. Appl. 2003, 18, 109-121. [CrossRef] [PubMed]

44. Cai, S.; Lei, T.; Li, N.; Feng, F. Effects of zn on microstructure, mechanical properties and corrosion behavior of Mg-Zn alloys. Mater. Sci. Eng. C 2012, 32, 2570-2577. [CrossRef]

45. Shi, Z.; Song, G.; Atrens, A. Corrosion resistance of anodised single-phase Mg alloys. Surf. Coat. Technol. 2006, 201, 492-503. [CrossRef]

(C) 2018 by the authors. Licensee MDPI, Basel, Switzerland. This article is an open access article distributed under the terms and conditions of the Creative Commons Attribution (CC BY) license (http://creativecommons.org/licenses/by/4.0/). 